\title{
Food Delivery Box Heating System
}

\author{
Nikunjchaudhari ${ }^{1}$,Yash $\operatorname{shah}^{2}$,Deep $\operatorname{shah}^{3}$, Amit patel $^{4}$ \\ ${ }_{1,2,3}$ (mechanical department,L.D.C.E,India) \\ ${ }^{4}$ (mechatronicsdepartment, Ganpat university,India)
}

\begin{abstract}
As we know that the food delivery is a major field now and needs to have improvement for maintaining proper quality of food as the present servicing system comprises an insulated box our project focus is on this area to enhance the existing system A system comprises a combination of heat exchanger utilizes the waste heat of said automobile exhaust and transfer it to said delivery box for maintaining the quality of food by maintaining the temperature. Said system has been integrated with sensors as well as flow control valves for improving the efficiency of the system.

Keywords: exhaust heat utilization, food delivery box, heating system, heat exchanger, flow control valve
\end{abstract}

\subsection{Problem summary}

\section{Introduction}

Online food business is increasing day by day. There are many problems regarding food delivery like bad quality, poor packing, different taste, timing, etc. When delivering perishable goods like meals it's very important for every business to make sure it reaches their foodies fresh, hot(or chilled) and exactly the way they want it to taste. But as we know that maintain temperature and quality of food in food delivery is the major problem. In a recent time, existing box as a insulating box is used, They are failed to maintain temperature in a long distance. Quality of food is also affected in a long distance. Nowadays there are many methods available for deliver heated food but some are ineffective, some are complex and costly. There is need for the improvement in present methods of food delivery. These conventional methods are failed to maintain temperature and quality of food for a period of time.

\subsection{Aim and Objectives of project}

Based on this realization, we are aiming to make the device that maintain temperature and quality of food as well as same in dimensions and cost to existing system. This food delivery system can capable to fulfill requirement of quality and temperature in long distance. This new mechanism will indirectly boost any economy that depends on food delivery. This device is useful to the restaurants, pizza outlets, and other ecommerce food companies. It is also very useful to the food delivery boy. It is easy to operate, does not need skilled labor, rapid, safe operation and simple maintenance. It is portable, it can be easily assembled and disassembled and it can be carried from one place to another. It reduces the risk of rejection of food and increase the relation of customers and restaurants (pizza outlets, e-commerce food business). So our main object is to develop such type of device which deliver best quality of food to the customers and improving the existing system.

\subsection{Previous work}

There is huge development in the field of food delivery starting from Dabbawala to improved insulated food delivery box across the globe. There are huge development in the corrugated box especially for the pizza. Even direct implementation of exhaust gas to the food delivery box for the purpose of heating which eventually leads to clogging of said pipe structure and even back pressureeffect is not been taken into account which leads to failure of said product

\section{Working Principle}

Heat transfer is the exchange of thermal energy between physical systems. Rate of heat transfer is dependent on the temperature of the systems and the properties of the medium throughwhich the heat is transferred. Our system is based on two mode of heat transfer which is conduction and convection

\subsection{Conduction}

conduction is a transfer of heat by microscopic collisions of particles and movement of the electrons within a body.

\subsection{Convection}

Convection is the transfer of heat from one place to other by the movement of fluids.

DOI: 10.9790/1684-1402012426 www.iosrjournals.org




\section{Construction And Working}

Simple design of our food delivery box system is shown in Fig. It contains three heat exchangers, connecting pipe.

\section{1working}

Low temperature fluid which is used in heat exchanger process goes to the coil type heat exchanger which is mounted on exhaust pipe of engine and takes the heat from the exhaust as in,equation(1) then it goes to the second heat exchanger which is mounted on fins of the engine and absorbs the heat from the fins making it as twin cooled engine. Now we have high temperature fluid which we will use to maintain the temperature of delivery box. This high temperature fluid goes to delivery box where it gives heat to food and maintain the temperature of food. This process is repeat again and again .for the selection of the fluid we use the various data's suggested in TABLE and as helium is having highest heat caring capacity along with this it's inert nature diminishes the adverse effect in the case of leakage. Due to said reason we choose the heat caring fluid ashelium. Even due to usage of gas there is no need of using separate pump which is another benefit of choosing the helium. For getting more heat content we use flow control valves which is utilized to make the contact for said time as much as we need to increase the heat gain.

$\operatorname{Equation}(\mathbf{1}), \mathbf{Q}=\mathbf{m} \times \mathbf{C} \times\left(\mathbf{T}_{\mathbf{f}}-\mathbf{T}_{\mathbf{i}}\right)$

\section{Equations}

$\mathrm{Q}=$ amount of heat energy gained or lost by fluid

$\mathrm{m}=$ mass of fluid

$\mathrm{C}=$ heat capacity $\left(\mathrm{J}^{\circ} \mathrm{C}^{-1} \mathrm{~g}^{-1}\right.$ or $\left.\mathrm{J} \mathrm{K}^{-1} \mathrm{~g}^{-1}\right)$

$\mathrm{T}_{\mathrm{f}}=$ final temperature

$\mathrm{T}_{\mathrm{i}}=$ initial temperature

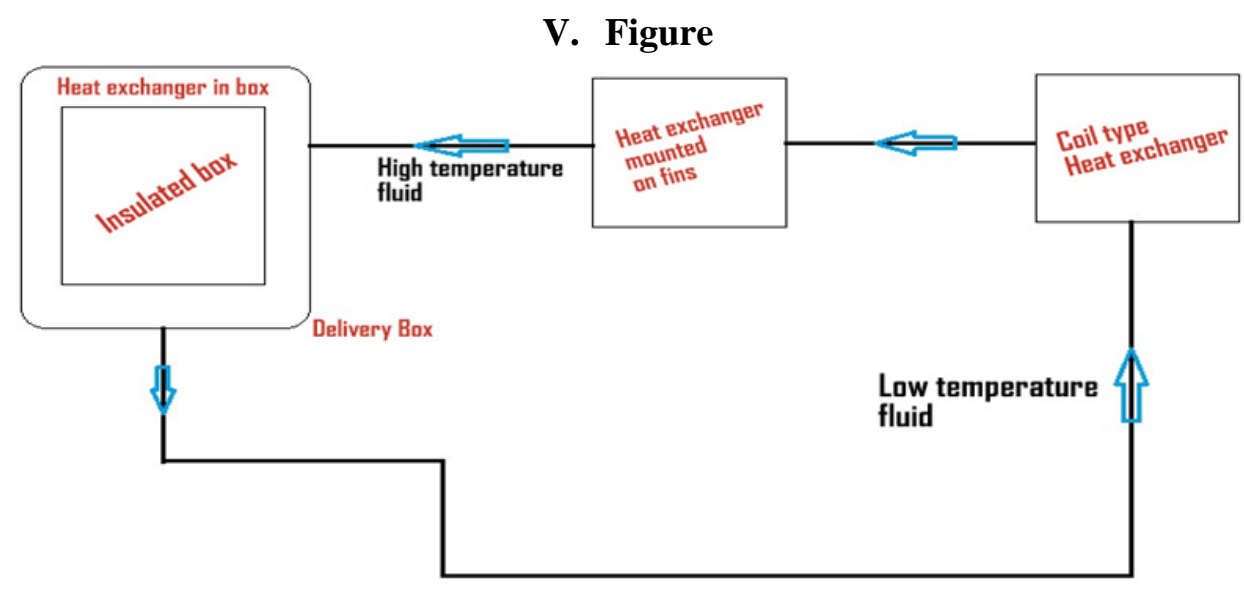

\section{Table}

\begin{tabular}{|c|c|c|c|c|c|c|c|c|}
\hline \multirow[b]{2}{*}{ Gas or Vapor } & \multirow[b]{2}{*}{ Formula } & \multicolumn{4}{|c|}{ Specific Heat } & \multirow{2}{*}{$\begin{array}{c}\begin{array}{c}\text { Specific } \\
\text { Heat Ratio }\end{array} \\
\kappa= \\
c_{p} / c_{v}\end{array}$} & \multicolumn{2}{|c|}{$\frac{\text { Individual Gas constant }}{-R-}$} \\
\hline & & $\begin{array}{c}c_{p} \\
(\mathrm{kN} /(\mathrm{kg} K))\end{array}$ & $\begin{array}{c}c_{V} \\
(k J)(k g K))\end{array}$ & $\begin{array}{c}c_{p} \\
\left(B \operatorname{tu}\left(\left({ }^{\prime} b_{m}{ }^{\circ} F\right)\right)\right.\end{array}$ & $\begin{array}{c}c_{v} \\
\left(B t u /\left(l b_{m}{ }^{\circ} F\right)\right)\end{array}$ & & $\begin{array}{c}c_{p}-c_{v} \\
(k N /(k g k))\end{array}$ & $\begin{array}{c}c_{p}-c_{V} \\
\left(f t / b_{p}\left(I b_{m}{ }^{\circ} R\right)\right)\end{array}$ \\
\hline Acetone & & 1.47 & 1.32 & 0.35 & 0.32 & 1.11 & 0.15 & \\
\hline Acetylene & $\mathrm{C}_{2} \mathrm{H}_{2}$ & 1.69 & 1.37 & 0.35 & 0.27 & 1.232 & 0.319 & 59.34 \\
\hline Air & & 1.01 & 0.718 & 0.24 & 0.17 & 1.40 & 0.287 & 53.34 \\
\hline Alcohol & $\mathrm{C}_{2} \mathrm{H}_{5} \mathrm{OH}$ & 1.88 & 1.67 & 0.45 & 0.4 & 1.13 & 0.22 & \\
\hline Alcohol & $\mathrm{CH}_{3} \mathrm{OH}$ & 1.93 & 1.53 & 0.46 & 0.37 & 1.26 & 0.39 & \\
\hline Ammonia & $\mathrm{NH}_{3}$ & 2.19 & 1.66 & 0.52 & 0.4 & 1.31 & 0.53 & 96.5 \\
\hline Argon & Ar & 0.520 & 0.312 & 0.12 & 0.07 & 1.667 & 0.208 & \\
\hline Benzene & $\mathrm{C}_{6} \mathrm{H}_{6}$ & 1.09 & 0.99 & 0.26 & 0.24 & 1.12 & 0.1 & \\
\hline Blast furnace gas & & 1.03 & 0.73 & 0.25 & 0.17 & 1.41 & 0.3 & 55.05 \\
\hline Bromine & & 0.25 & 0.2 & 0.06 & 0.05 & 1.28 & 0.05 & \\
\hline Butatiene & & & & & & 1.12 & & \\
\hline Butane & $\mathrm{C}_{4} \mathrm{H}_{10} \mathrm{O}$ & 1.67 & 1.53 & 0.395 & 0.356 & 1.094 & 0.143 & 26.5 \\
\hline Carbon dioxide & $\mathrm{CO}_{2}$ & 0.844 & 0.655 & 0.21 & 0.16 & 1.289 & 0.189 & 38.86 \\
\hline Carbon monoxide & $\mathrm{CO}^{-}$ & 1.02 & 0.72 & 0.24 & 0.17 & 1.40 & 0.297 & 55.14 \\
\hline Carbon disulphide & & 0.67 & 0.55 & 0.16 & 0.13 & 1.21 & 0.12 & \\
\hline Chlorine & $\mathrm{Cl}_{2}$ & 0.48 & 0.36 & 0.12 & 0.09 & 1.34 & 0.12 & \\
\hline Chloroform & & 0.63 & 0.55 & 0.15 & 0.13 & 1.15 & 0.08 & \\
\hline Coal gas & & 2.14 & 1.59 & & & & & \\
\hline Combustion products & & 1 & & 0.24 & & & & \\
\hline Ethane & $\mathrm{C}_{2} \mathrm{H}_{6}$ & 1.75 & 1.48 & 0.39 & 0.32 & 1.187 & 0.276 & 51.5 \\
\hline Ether & & 2.01 & 1.95 & 0.48 & 0.47 & 1.03 & 0.06 & \\
\hline Ethylene & $\mathrm{C}_{2} \mathrm{H}_{4}$ & 1.53 & 1.23 & 0.4 & 0.33 & 1.240 & 0.296 & 55.08 \\
\hline $\begin{array}{c}\text { Monochlorodifluoromethane, } \\
\text { R-22 }\end{array}$ & & & & & & 1.18 & & \\
\hline Helium & $\mathrm{He}$ & 5.19 & 3.12 & 1.25 & 0.75 & 1.667 & 2.08 & 386.3 \\
\hline Hexane & & & & & & 1.06 & & \\
\hline
\end{tabular}




\section{Acknowledgement}

I wish to make sincere thanks to prof. D.U.Panchal for his valuable guidance and encouragement.

\section{Conclusion}

There are lots of problems in delivery of food because of several reasons, many designs are developed to improve the delivery of food but all of them are not able to solve all the problems which faced in delivery of food. Depending upon the necessity the suitable mechanism needs to be selected. As mentioned above the system serves to innumerous people with novel system of heating of food. it gives not only the quality but also the enjoyment so overall we can deduce that our system works for a good cause.We also admit it that there can be more integrations to our suggested system.

\section{References}

[1]. $\quad$ Er. R. K. Rajput., "Heat and mass transfer, Fifth edition," (S. Chand Technical, 2012), 1-24, ISBN: 81-219-2617-3

[2]. Kothandaraman, C.P., Subramanyan, S., "Heat and Mass Transfer Data Book, Seventh Edition

[3]. I.C. ENGINE BY V. GANESAN

[4]. Mr. Krishna Asawa, Prof. VaibhavDighe,Mr. KhanduMahanor, Miss. UtkarshaKharade AND Miss. VinayaKulkarni “USE OF EXHAUST GAS HEAT TO KEEPFOOD DELIVERY ITEM WARM'IN IJARIIE-ISSN(O)-2395-4396 Vol-2 Issue-3 2016

[5]. Lawrence H Horwitz "Reusable thermally insulated food delivery box" US patent US5190213 